\title{
Retraction Note to: New Horizons in Genitourinary Oncologic Imaging
}

\section{H. Hricak}

Department of Radiology, Memorial Sloan-Kettering Cancer Center, 1275 York Avenue, Room C-278, New York, NY 10021, USA

\section{Retraction to: Abdom Imaging DOI 10.1007/s00261-005-0385-6}

This review article has been retracted upon the request of the author as it contains similar text and illustrations to previously published articles. For further information, please contact the author Hedvig Hricak, MD at hricakh@mskcc.org.

The online version of the original article can be found under doi:10.1007/s00261-005-0385-6.

Correspondence to: H. Hricak; email: hricakh@mskcc.org 